\title{
Social Gain or Social Pain: Subjective Socio-economic Status, Income and Attitudes towards Social Relations
}

\author{
Aistė Diržyte் ${ }^{1}$, Aleksandras Patapas ${ }^{2}$ \\ ${ }^{1}$ Professor at the Vilnius Gediminas Technical University, LT-10223, 11 Sauletekio Al., Vilnius, Lithuania, \\ Professor at the Mykolas Romeris University, LT 08303, 20 Ateities Str., Vilnius, Lithuania, ${ }^{2}$ Associate Professor \\ at the Mykolas Romeris University, LT 08303, 20 Ateities Str., Vilnius, Lithuania
}

\begin{abstract}
Social pain is usually defined as the experience of pain because of interpersonal rejection or loss. The aim of this study was to find out the peculiarities of attitudes towards social relations in different groups of income and perceived socio-economic status in a representative sample of Lithuanian population $(\mathrm{n}=1001)$. We have found that mean ranks in the lowest-income quintile, agreeing that "my relationships are supportive and rewarding", were almost twice lower than in the highest-income quintile. A similar tendency was observed with the statements "I actively contribute to the happiness and well-being of others" and "People respect me". Mean ranks in the subjectively poorest group regarding perceived respect from people were almost three times lower than in the subjectively rich group. It appears that having low income and low subjective socio-economic status may harm psychological wellbeing. Our study raises concern regarding societal wellbeing: we suggest that in order to achieve the prosperity of society, it is necessary to reduce socioeconomic inequalities and through various programs and projects strengthen people's ability to establish and maintain supportive, compassionate social contacts.
\end{abstract}

Keywords: Subjective perceptions, public administration, social relationships, social connections.

\section{Introduction}

Interest in the influence of social relationships on psychological well-being has a long history, starting with works of E. Durkheim (1897/1951), J. Bowlby (1969) and many others. Recently, researchers worldwide haveinvestigated positive as well as challenging aspects of social relationships, including social power, ${ }^{1}$ social class, ${ }^{2}$ or aggression. ${ }^{3}$ Some researchers havesuggested central role of morality in social connections and revealed that supportive social relations reduce the adverse consequences of a wide variety of stressful life events, contributes to psychological well-being irrespective of the level of life stress, and may enhance overall subjective well-being. ${ }^{4}$ Some researchers investigated whetherlow (vs. high) subjective socioeconomic status increase both prosociality and aggression, ${ }^{5}$ and some have found that we choose our social ties because of their capacity to provide rewards relative to costs, and our choices lead to construct social networks composed pre-dominantly of rewarding social ties. Person perception studies show that negative information about others has higher impact than positive information, and unpleasant encounters with bureaucracies are far more predictive ofclients' overall evaluation of services provided than are pleasant encounters.

Research on societal quality of life has established social relationships as extremely important factor in the psychological well-being of society. Researchers argue that we are "social animals" who, through relationships with others, can experience the joy of life, discover the meaning of life, as other people are the most important objects in our world. ${ }^{6}$ If one succeeds in establishing and managing social relationships in a qualitative manner, it may determine the ability to experience the fullness of life. ${ }^{7.8}$ In addition, relationships with other people are reflected in best life experiences. ${ }^{9}$

Research shows that social relationships are better predictors of our own well-being than higher income: "people are firmly anchored in social networks, and 
person's health and well-being affects the health and well-being of another because human happiness is not the happiness of isolated individuals". ${ }^{10}$ Social relationships also link to mental and physical health: individuals living alone or having no close friends are twice as likely to suffer from cardiovascular disease; they are more likely to have infectious or respiratory diseases. Quality of social connections determines the speed of wound healing: if a person has very poor quality social relationships, wounds heal twice slower than in a group of people having supporting and satisfactory social relationships. ${ }^{7}$ Deprived social connections relates to social exclusion: exclusion means that a person is geographically present in a society but cannot participate actively as other citizens. ${ }^{11}$ Research has shown that in some countries poor people, especially children or youth, may suffer social exclusion or stigma and related bullying. Due to a lack of material resources,some people may not be able to get proper education and achievetheir goals in the labour market. ${ }^{12}$

For decades, researchers have been interested in how exclusion affects person's social relationships, or whether being the poorest member of society results in social stigma and consequent social pain. ${ }^{13}$ This research is extremely important as it demonstrates that social pain could also arise from social comparisons, perceptions regarding personal income or socio-economic status, and not only because of interpersonal rejection or loss.Research has also demonstrated positive value of personal initiative to be an active member of society. Some researchers revealed that not only qualitative social relationships, but also any contribution to society can increase quality of life: altruistic social behaviour, community engagement and group assistance aimed at helping others positively links to longevity, help overcome stress and negative emotions. ${ }^{14}$

By magnetic resonance, neurobiologists have found that some parts of the brain activate at the time we receive money so that we experience pleasure. However, when we give money to other people for charitable purposes, our brain activates in a way that gives us even more pleasure. Thus, social relationships are crucial to the quality of life. According to research, many people in the world suffer from low self-esteem and lack of willingness to live, which can lead to their diminished economic value. ${ }^{15}$ In order to make effective public administration or social policy decisions, it is important to clarify factors possibly related to people's economic value and societal wellbeing. This study aimed at analysing Lithuanian population attitudes towards social relationships in different income and perceived socioeconomic status groups. We hypothesised that income or perceived socio-economic status relates to different attitudes towards social relations.

\section{Materials and Method}

The study of Lithuanian population was carried out by multilevel probability sampling. The overall number of respondents was 1001. To measure attitudes towards social relationships, we used Psychological Flourishing scale created by Ed Diener. ${ }^{16}$ The Flourishing Scale is a brief 8-item summary measure of the respondent's self-perceived success in important areas such as relationships, self-esteem, purpose, and optimism. The scale provides a single psychological well-being score. However, we have selected 3 items for this survey:"People respect me"; "My social relationships are supportive and rewarding"; "I actively contribute to the happiness and well-being of others".

Objective and subjective indicators relate to socioeconomic status. Objective indicators include, for example, personal income, and subjective indicators include, for example, perceived socio-economic stratification. We evaluated the objective socioeconomic status according to the person's income. We subdivided the study sample into income quintiles. In the lowest income group, quintile Q1, there were 17.2 percent of the respondents. In Q2, the second quintile, there were 19.9 percent, in Q3, the third quintile, there were 24.9 percent, in Q4, the fourth quintile, there were 19.4 percent, and in Q5, the fifth quintile, the highest income group, there were 18.7 percent of respondents.

Because the data were distributed asymmetrically across the groups, non-parametric statistics were used to analyse the data, and Kruskal-Wallis independent sample intergroup comparisons were performed. The limitations of this part of the analysis are, of course, the specifics that other assets or debts of the individual were not taken into account, because the income received monthly does not necessarily reflect the actual economic situation of the individual.

In this study we aimed to evaluate the role of subjective socio-economic stratification, therefore we have also analysed subjective socio-economic status assessment. We applied the modified Subjective Social Class Measure, which measures a person's subjective socio-economic status, and based on the results, we divided the respondents into 5 groups: 
- affiliating themselves with the wealthy, who live a rich and privileged life, who have a lot of money and feel themselves as VIP;

- assigning themselves to the middle class who have enough money to live a normal life;

- assigning themselves to the middle class, who sometimes have limited amounts of money;

- affiliating themselves with the poor, who have no money for a normal life;

- assigning themselves to the poorest of the poor who do not have the money for basic everyday needs.

According to the subjective assessment of the socioeconomic situation, only one person attributed himself to the rich, so we did not investigate this further. As the remaining four groups were distributed asymmetrically, non - parametric statistics were used to analyze the data, and Kruskal-Wallis independent sample intergroup comparisons were performed.

\section{Resultsand Discussion}

To determine whether groups of different income quintiles differ in their attitudes towards social relationships, we performed Kruskal-Wallis cross-group comparisons of independent samples. The results of the study showed statistically significant differences in attitudes towards social relationships between different groups of income quintiles (Table 1). Mean ranks in the lowest-income quintile Q1, agreeing that "my relationships are supportive and rewarding", were almost twice lower than in the highest-income quintile Q5 $(\mathrm{H}(2)=127.585, \mathrm{p}=0.000)$. A similar tendency is observed for the statement "I actively contribute to the happiness and well-being of others", with mean ranks in the lowest income quintile Q1 being almost twice lower than in the highest income quintile Q5 (H (2) $=110.829$, $\mathrm{p}=0.000)$.

Table 1. Intergroup comparisons of income quintile independent samples by attitudes, Kruskal-Wallis test $(n=1001)$

\begin{tabular}{|c|c|c|c|c|c|c|}
\hline & Income quintiles & $\mathbf{N}$ & Mean ranks & H (2) Chi square & df & $\mathbf{p}$ \\
\hline \multirow{5}{*}{$\begin{array}{l}\text { "My social relationships are supportive } \\
\text { and rewarding" }\end{array}$} & Q1 & 172 & 357.18 & \multirow{5}{*}{127.585} & \multirow{5}{*}{4} & \multirow{5}{*}{$<0.001$} \\
\hline & Q2 & 199 & 453.67 & & & \\
\hline & Q3 & 249 & 474.18 & & & \\
\hline & $\mathrm{Q} 4$ & 194 & 545.10 & & & \\
\hline & Q5 & 187 & 673.61 & & & \\
\hline \multirow{5}{*}{$\begin{array}{l}\text { "I actively contribute to the happiness } \\
\text { and well-being of others" }\end{array}$} & Q1 & 172 & 356.19 & \multirow{5}{*}{110.829} & \multirow{5}{*}{4} & \multirow{5}{*}{$<0.001$} \\
\hline & Q2 & 199 & 451.22 & & & \\
\hline & Q3 & 249 & 487.02 & & & \\
\hline & Q4 & 194 & 556.18 & & & \\
\hline & Q5 & 187 & 648.54 & & & \\
\hline
\end{tabular}

To find out whether subjective stratification, selfattribution to different socio-economic status groups is associated with different evaluations of the quality of social relationships, we performed Kruskal-Wallis crossgroup comparisons of independent samples. As shown in Table 2, the results of the study indicated statistically significant differences between the different groups of subjective socio-economic stratification. The mean ranks in the subjectively poorest group, agreeing that "my relationships are supportive and rewarding", were almost three times lower than in the subjectively rich group $(H(2)=130.374, p=0.000)$. A similar tendency is observed for the statement "I actively contribute to the happiness and well-being of other people" - the average ranks in the subjectively poorest group were almost twice lower than in the subjectively rich group $(\mathrm{H}(2)=$ 111.070, $\mathrm{p}=0.000$ ).

To find out whether groups of different income quintiles differ in perceived respect from people, we 
performed Kruskal-Wallis cross-group comparisons of independent samples. As we can see in Table 3, the results of the study showed statistically significant differences in perceived respect from people among different income quintile groups. Mean ranks in the lowest-income quintile Q1, agreeing that "people respect me", were almost twice lower than in the highest-income quintile Q5 (H (2) $=69.904, \mathrm{p}=0.000)$.

Table 2. Intergroup comparisons of subjective socioeconomic stratification by attitudes to others, KruskalWallis Test $(\mathbf{n}=998)$

\begin{tabular}{|c|c|c|c|c|c|c|}
\hline & Subjective socio-economic stratification & $\mathbf{N}$ & $\begin{array}{l}\text { Mean } \\
\text { ranks }\end{array}$ & $\begin{array}{c}\text { H (2) Chi } \\
\text { square }\end{array}$ & df & $\mathbf{p}$ \\
\hline \multirow{4}{*}{$\begin{array}{l}\text { "My social } \\
\text { relationships are } \\
\text { supportive and } \\
\text { rewarding" }\end{array}$} & Middle class, enough money & 125 & 612.76 & \multirow{4}{*}{130.374} & \multirow{4}{*}{3} & \multirow{4}{*}{$<0.001$} \\
\hline & Middle class, not enough money & 552 & 554.60 & & & \\
\hline & Poor, not enough money & 276 & 381.07 & & & \\
\hline & Poorest of the poor & 45 & 235.32 & & & \\
\hline \multirow{4}{*}{$\begin{array}{l}\text { "I actively } \\
\text { contribute to the } \\
\text { happiness and well- } \\
\text { being of others" }\end{array}$} & Middle class, enough money & 125 & 578.58 & \multirow{4}{*}{111.070} & \multirow{4}{*}{3} & \multirow{4}{*}{$<0.001$} \\
\hline & Middle class, not enough money & 552 & 554.43 & & & \\
\hline & Poor, not enough money & 276 & 399.88 & & & \\
\hline & Poorest of the poor & 45 & 217.04 & & & \\
\hline
\end{tabular}

Table 3. Intergroup comparisons of income quintile independent samples by perceived respect from people, Kruskal-Wallis test $(n=1001)$

\begin{tabular}{|c|c|c|c|c|c|c|}
\hline & Income quintiles & $\mathbf{N}$ & Mean ranks & H (2) Chi square & \multicolumn{2}{|c|}{ Dfp } \\
\hline \multirow{5}{*}{ "People respect me" } & Q1 & 172 & 385.05 & \multirow{5}{*}{69.904} & \multirow{5}{*}{4} & \multirow{5}{*}{$<0.001$} \\
\hline & Q2 & 199 & 474.41 & & & \\
\hline & Q3 & 249 & 480.99 & & & \\
\hline & Q4 & 194 & 548.29 & & & \\
\hline & Q5 & 187 & 613.54 & & & \\
\hline
\end{tabular}

To find out whether subjective stratification, selfattribution to different socio-economic status groups is associated with different evaluations of perceived respect from people, we performed Kruskal-Wallis cross-group comparisons of independent samples. As we can see in Table 4, the results of the study showed statistically significant differences in perceived respect for people among the different groups of subjective socio-economic stratification $(\mathrm{H}(2)=78.111, \mathrm{p}=0.000)$, with mean ranks in the subjectively poorest group almost twice lower than in the subjectively rich group.

Table 4. Inter-group comparisons of subjective socio-economic stratification by perceived respect from people, Kruskal-Wallis test $(\mathrm{n}=998)$

\begin{tabular}{|c|c|c|c|c|c|c|}
\hline & Subjective socio-economic stratification & $\mathbf{N}$ & $\begin{array}{l}\text { Mean } \\
\text { ranks }\end{array}$ & $\begin{array}{c}\text { H (2) Chi } \\
\text { square }\end{array}$ & df & $\mathbf{p}$ \\
\hline \multirow{4}{*}{ "People respect me" } & Middle class, enough money & 125 & 552.73 & \multirow{4}{*}{78.111} & \multirow{4}{*}{3} & \multirow{4}{*}{$<0.001$} \\
\hline & Middle class, not enough money & 552 & 547.64 & & & \\
\hline & Poor, not enough money & 276 & 417.03 & & & \\
\hline & Poorest of the poor & 45 & 266.90 & & & \\
\hline
\end{tabular}


To sum up, the Lithuanian population's survey revealed statistically significant differences in attitudes towards social relationships between different income quintile groups. In the Lithuanian population, the mean ranks in the lowest income quintile, agreeing that "my relationships are supportive and rewarding", are almost twice lower than in the highest income quintile. A similar tendency is observed with the statements "I actively contribute to the happiness and well-being of others" and "People respect me". ${ }^{17}$ It appears that having low subjective socio-economic status may harm psychological wellbeing. Our study raises concern regarding societal wellbeing, especially, having in mind some of the studies reporting that lower class participants respond with greater hostile reactions to threat than do upper class participants ${ }^{2,18}$ or that low subjective socioeconomic status is related to increased aggression. ${ }^{19,20}$

\section{Conclusions}

The results of the study revealed statistically significant differences in attitudes towards social relationships between different income quintile groups. Mean ranks in the lowest-income quintile Q1, agreeing that "my relationships are supportive and rewarding", were almost twice lower than in the highest-income quintile Q5. A similar tendency observed with the statement "I actively contribute to the happiness and well-being of others". The results of the study showed statistically significant differences between different groups of subjective socio-economic stratification. Mean ranks in the subjectively poorest group were almost three times lower than in the subjectively rich group. A similar tendency observed with the statement "I actively contribute to the happiness and well-being of others".

The results of the study showed statistically significant differences in perceived respect from people among different groups of subjective socioeconomic stratification, where the average ranks in the subjectively poorest group were almost twice lower than in the subjectively rich group. It appears that having low income and low subjective socio-economic status may harm psychological wellbeing. Our study raises concern regarding societal wellbeing. In order to achieve the prosperity of society, it is necessary to reduce socioeconomic inequalities and through various programs and projects strengthen people's ability to establish and maintain supportive, compassionate social contacts.

Acknowledgments: None.
Conflict of Interest: There is not conflict of interest.

Ethical Clearance: All procedures performed in studies involving human participants were in accordance with the ethical standards of the institutional and national research committee and with the 1964 Helsinki declaration and its later amendments or comparable ethical standards. Informed consent was obtained from all individual participants included in the study. A study was approved by National Ethics Committee for Research in Health of Lithuania, November 27, 2019, No 348621-LK.

Source of Funding: Self-funding.

\section{References}

1. Lammers J., Stoker J.I. Social and personal power: a closer examination: an invited commentary to Mayiwar and Lai. Social Psychology, 2019, 50(4): 270-275.

2. Kraus M.W., Stephens N.M. A road map for anemerging psychology of social class. Social and Personality Psychology Compass, 2012, 6: 642656.

3. Baker E.R., Jensen C.I., Moeyaert M., Bordoff S. Socioeconomic status and early childhood aggression: moderation by theory of mind for relational, but not physical, aggression. Early Child Development and Care, 2018. Available at: https:// www.tandfonline.com/doi/full/10.1080/03004430. 2018.1524379.

4. Prati F., Moscatelli S., Van Lange P.A.M., Van Doesum N.J., Rubini M. The central role of morality in perceived humanness and unselfish behaviors. Social Psychology, 2018, 49(6): 330-343.

5. Greitemeyer T., Sagioglou C. Does low (vs. high) subjective socioeconomic status increase both prosociality and aggression? Social Psychology, 2018, 49(2): 76-87.

6. Boehm J.K., Lyubomirsky S. The promise of sustainable happiness. Handbook of Positive Psychology. Oxford: Oxford University Press, 2009.

7. Seligman M. Flourish: a visionary new understanding of happiness and well-being. New York: Free Press, 2011.

8. Dush C.M.K., Amato P.R. Consequences of relationship status and quality for subjective wellbeing. Journal of Social and Personal Relationships, 2005, 22: 607-627. 
9. Csikszentmihalyi M., Csikzsentmihalyi I.S. A life worth living: contributions to positive psychology (series in positive psychology).New York: Oxford University Press, 2006.

10. Diener E., Seligman M.E.P. Beyond money: toward an economy of well-being. Psychological Science in the Public Interest, 2004, 5: 1-31.

11. Tov W., Diener E. The well-being of nations: linking together trust, cooperation, and democracy. Dordrecht: Springer, 2009.

12. Lyubomirsky S., Kasri F. Levels of private selfconsciousness and mood awareness among happy and unhappy individuals, 2006. Available at: http:// sonjalyubomirsky.com/files/2012/09/BoehmLyubomirsky-2009.pdf.

13. Gudmundsdottir D. The impact of economic crisis on happiness. Social Indicators Research, 2013, 110(3): 1083-1101.

14. Kapteyn A., Smith J.P., Van Soest A. Are Americans really less happy with their incomes? Review of Income \& Wealth, 2013, 59(1): 44-65.

15. Trung N., Cheong K., Nghi P., Kim W. Relationship between socio-economic values and wellbeing: an overview research in Asia. Social Indicators Research, 2013, 111(2): 453-472.

16. Diener E., Wirtz D., Tov W., Kim-Prieto C., Choi D., Oishi S., Biswas-Diener R. New measures of well-being: flourishing and positive and negative feelings. Social Indicators Research, 2009, 39: 247266.

17. Sirgy M.J. The psychology of quality of life. Hedonic well-being, life satisfaction, and eudaimonia. Berlin: Springer Science+Business Media B.V., 2012.

18. Guillen-Royo M., Velazco J., Camfield L. Basic needs and wealth as independent determinants of happiness: an illustration from Thailand. Social Indicators Research, 2013, 110(2): 517-536.

19. Greitemeyer T., Sagioglou C. Increasing wealth inequal-ity may increase interpersonal hostility: the relationship between personal relative deprivation and aggression. The Journal of Social Psychology, 2017, 157: 766-776.

20. Boes S., Winkelmann R. The effect of income on general life satisfaction and dissatisfaction. Social Indicators Research, 2010, 95(1): 111-128. 